"To identify and review the effective factors of attracting and retaining professional physicians in management of social security of Tehran province and ITS subordinate units"

$\begin{array}{ll}\text { AUTHORS } & \text { Ramin Varan } \\ & \text { Maryam Rostami }\end{array}$

Ramin Varan and Maryam Rostami (2016). To identify and review the effective factors of attracting and retaining professional physicians in management of

ARTICLE INFO social security of Tehran province and ITS subordinate units. Problems and Perspectives in Management, 14(3-si), 414-421. doi:10.21511/ppm.14(3si). 2016.16

DOI http://dx.doi.org/10.21511/ppm.14(3-si).2016.16

RELEASED ON Thursday, 15 September 2016

JOURNAL

"Problems and Perspectives in Management"

FOUNDER

LLC "Consulting Publishing Company "Business Perspectives"

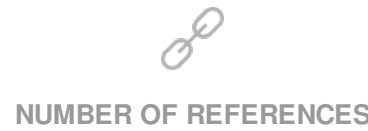

0
NUMBER OF FIGURES

0
NUMBER OF TABLES

0

(C) The author(s) 2022. This publication is an open access article. 
Ramin Varan (Iran), Maryam Rostami (Iran)

\title{
To identify and review the effective factors of attracting and retaining professional physicians in management of social security of Tehran province and ITS subordinate units
}

\begin{abstract}
The importance of human resource cannot be ignored in today's global and complicated environment. The importance of human resource management and especially, human resource talent management, would appear in a point that, in the new economy, the important resource for economy, is knowledge and, in this current era, human resource knowledge is a competitive advantage and in among other manufacturing factors is as an important factor and also invisible organizational assets that, in organizational structures and process would, apply and make possible the situation to innovation. Regarding to this situations, attracting and retaining human resources in organizations are facing to its complicities and challenges, without focusing on the effective factors on it and also non-recognition, human resource management project would face with failure undoubtedly. Secondary data were collected via library study and with using of the questionnaire made by the researcher and, then, the basic information research was collected that validity and variables was verified formally and also the questionnaire reliability with a pre- testing by using of Cronbach's Alpha test that was equal with 0.89 was verified. Statistical Society is the all professional physicians in the management of Social Security of Tehran province and its subordinate units and based on Morgan Krejcie table in 95 percent confidence level, between 1272 persons in the mentioned statistical society, 259 persons were selected as sample research. In order to analyze the data, descriptive statistics and inferential statistics are used. Friedman test is used for ratings research's variables by helping SPSS software.

The results reveal that about $50 \%$ of female responders and the rest of that were males and over $85 \%$ of responders were physicians and about $75 \%$ of responders were having a professional PHD degree and the rest of them were having a master degree and about $61 \%$ were having job's history who were over 20 years old.
\end{abstract}

Keywords: attracting and retaining, organizational talents, talent management, human resource management, professional physicians, management of remedy social security.

JEL Classification: M12. M55, O15.

\section{Introduction}

The human resource title, because of its complexity focuses on the human reality and also having the relationships of the field of human presence and wonderful elegance that the amount of conception that are related to this field, is an evidence for this claim. Human resource management is involving with titles such as attracting, retaining and promotion with extensive conception like training and learning, organizational culture, motivation, work perceptions, trust, etc.

The human factor in the organization as a vital item in achieving to organizational aims and all the people are applying in the different organizational level that are having the ability of learning, changing, innovation and creativity with suitable motivation for reaching to special and valuable organizational targets (Arabi, 1389). The most important factor to improving in each organization and in each the country, is human forces. So that this factor turned into a vital and important factor in determining the existence different in productivity and its growth in different countries (Bahadori, Tymor zadeh, Farahani, 1392).

(C) Ramin Varan, Maryam Rostami, 2016.

Ramin Varan, Department of Mnagement Sciences, Firouzkouh Branch, Islamic Azad University, Firouzkouh, Iran.

Maryam Rostami, Master of Accounting, Abu Rayhan Polyclinic, Social Security Organization, Tehran, Iran.
To gaining and recruitment the capable employees with competence, skills, knowledge and the necessity potential for passing the future training. the methods of selecting and recruitment staff that can provide these organizational needs in a good way, must consider the main activities for organizations and the others human resource policies should be based on this rules (Kip, 1989). The organization strategic ability is depending on their resource capability in the form of staff that is the basic recruitment strategy. By helping this strategy, we can select the capable staffs and in comparing with the rivals will reach to a competitive advantage as soon as them. These experts, according to their skills and competencies, play an important role in the organization success. The human resource retaining system has many dimensions that can be divided into 2 categories in general:

1. The items are more related to retaining and reinforcing staff's body such as linking the hygiene and safety in the workplace, implementing the sports programs and healthy and some other service personnel.

2. Items that reinforcing the willing and staff favorites to work and workplace such as creating job security, providing life in percent, senior citizens lifetime and retirement, job's satisfaction and other similar cases. 
It is necessary to express that to maintaining of staff's body and their mental healthy as two different titles that both of those aren't different to each other, for example, providing hygiene in work pace hasn't any effect on reinforcing willing and employee satisfaction and doing safety activities even though would face with negative opposition and resistance employees, at last, won't cause for calmness and reducing concerns of risk. Of course, these two dimensions effect to each other and are almost inevitable. One of the outputs and results that were expected from maintenance system is coordinating the services and activities that used in order to staff's welfare. Finally, it will provide their satisfaction related to society targets. Such as the management efforts to retaining and maintenance of human resource is creating staff's satisfaction and preventing of its dissatisfaction. In this case, there are different opinions and questions. Here we only indicate to the findings and opinions that are related to human resource maintenance. Due to organizational hygiene theory, the management activities in order to staffs issues can be divided into two categories:

1. The activities that cause to reducing staffs dissatisfactions.

2. The activities that cause to creating staff satisfactions.

The results of the above theory that there are a direct and positive correlation between the satisfaction factor and continued staff service in the organization. In other words, how much the level of staff satisfaction from their work situation be higher, the possibility that they want to leave their workplace is lower and how much dissatisfaction would be higher, then being absence, resigned and escape from institute would be higher. In addition, we shouldn't imagine that all of the people that left the organization, their existence was useful for the organization. According to the past research, we can express that the worst people in every organization are who didn't have job satisfaction but they were forced to stay in the organization. Tables 1-2 show the people category in organization into 4 categories.

Table 1 . The people category in the organization

\begin{tabular}{|l|l|l|}
\hline & \multicolumn{1}{|c|}{ Having job satisfaction } & \multicolumn{1}{c|}{ Having job dissatisfaction } \\
\hline $\begin{array}{l}\text { Favorable } \\
\text { environment }\end{array}$ & $\begin{array}{l}\text { Stay in the organization } \\
\text { because they are forced }\end{array}$ & Stay in the organization \\
\hline $\begin{array}{l}\text { Unfavorable } \\
\text { environment }\end{array}$ & $\begin{array}{l}\text { Would leave the } \\
\text { organization }\end{array}$ & $\begin{array}{l}\text { Stay in the organization and they } \\
\text { are hoping to improving the } \\
\text { environment }\end{array}$ \\
\hline
\end{tabular}

\section{The components of recruitment strategy}

1.1. Human resource planning: evaluating the future needs and making a decision about the amount and kind of requirement staff.

1.2. Recruitment plans: providing plans for exploring and finding staff from the internal and external organization and training them to using by their skills.
1.3. Maintenance strategy: planning for enhancing the flexibility in order to use the maximum human resource productivity so that would use of their staff and to matching and to being compatible itself with the changes.

1.4. Talent management strategy: making sure that the organization have smart staff and needs them for replacing for management and providing to the future and current needs.

Right (2008) is believed that talent management as a system to identify, hire, develop, upgrade and maintenance of suitable people with the purpose of optimizing the power of organization in order to the realization of business results that systemically cover the gap between the organization current talents and needed talents in order to respond the organization's current and future challenges in their business. Talent management has many economic benefits. These economic benefits were proved in organization level and also in individual. Due to this, we won't imagine that talent management is a process that will finish during 3 months. Of course, it includes integrated planning that many factors are involved with it and one part of human resource won't take responsibility, that this issue will face talent management with problems and takes time, but it is valuable (Heinen, 2004).

Beyond of keeping staff satisfaction, there is a financial reasonable logic. If the staff made a decision to leave the organization, the replacement cost may be more than two and a half times that she/he is received. This shocking ratio that was examined in 444 North America companies in 2006 by managerial consultant right (a global company organizational leading to consultant and job changing). So a number like this when is significant that the cost of hiring, training and separation along with lost productivity would add. In fact, about $45 \%$ of the responder companies were expressed that replacing of e new smart and talent workforce has a cost equal with three times employee's salary (Righ Management, 2006).

\section{Background and literature}

Job satisfaction, interest and loyalty to the organization and staff thriving are related to responsible management and its owner. To identify the effective factors in creating the satisfaction and the items for staff dissatisfactions and also the evaluating of their job satisfaction play an important and key role that also have the considerable role in order to achieving to the mentioned aims (Haji Karimi, 1389).

The study that has done by Foroghi (1391) related to talent management in current world, it reveals that existence talent and its retaining, would appear the creativity, efficiency and effectiveness and the leadership items in the organization and human 
resource retaining system includes several dimensions than can be divided into two categories:

1. Items that are more related to keeping and reinforcing the staff body: linking hygiene and safety in workplace, implementation of sports plans and being healthy and some other personnel service.

2. The items that improve spirit and staffs willing for working and work environment such as creating job safety, life providing in the present, the senior citizen lifetime and retirement, job satisfaction and others similar items. The human resource maintenance title that includes two dimensions such as the mental healthy and being well is an extensive territory that the items such as hygiene and healthy, insurance and retirement and welfare utilities, all of those are the smaller part of it.

Mahmodi (1291) in a study has examined to identifying and ranking the effective factors on talent management, recruitment and human capital retaining using with MCDM procedure in the Kharazmi university that this research in term of practical is quantity and deceptive and its statistical society was the student of Kharazmi university in master degree level in 1392 to 1393 . Sampling is a simple randomly procedure and the data collecting is a questionnaire with 6 dimensions and 35 sub-indexes. For this aim, there were about 217 students in master degree level and selected about 220 questionnaires were distributed that finally we collected 188 questionnaires. as well as, for data analysis was used Topsis technique, Fazzy Topsis and integrated method, the results of applying these techniques "the university research atmosphere" as an important dimension and "the existence of training facilities and education" were introduced as the most important of sub-indexes.

\section{Conceptual model}

Given that this study is examining in a limited statistical society for the first time, the under conceptual model derived of related literature, research framework and the main model in Figures 2-12 as conceptual model for identifying and examining the effective factors on recruitment and maintenance professional physicians in Tehran city's management of remedy social security and its subordinate units as the implementation research model was selected.

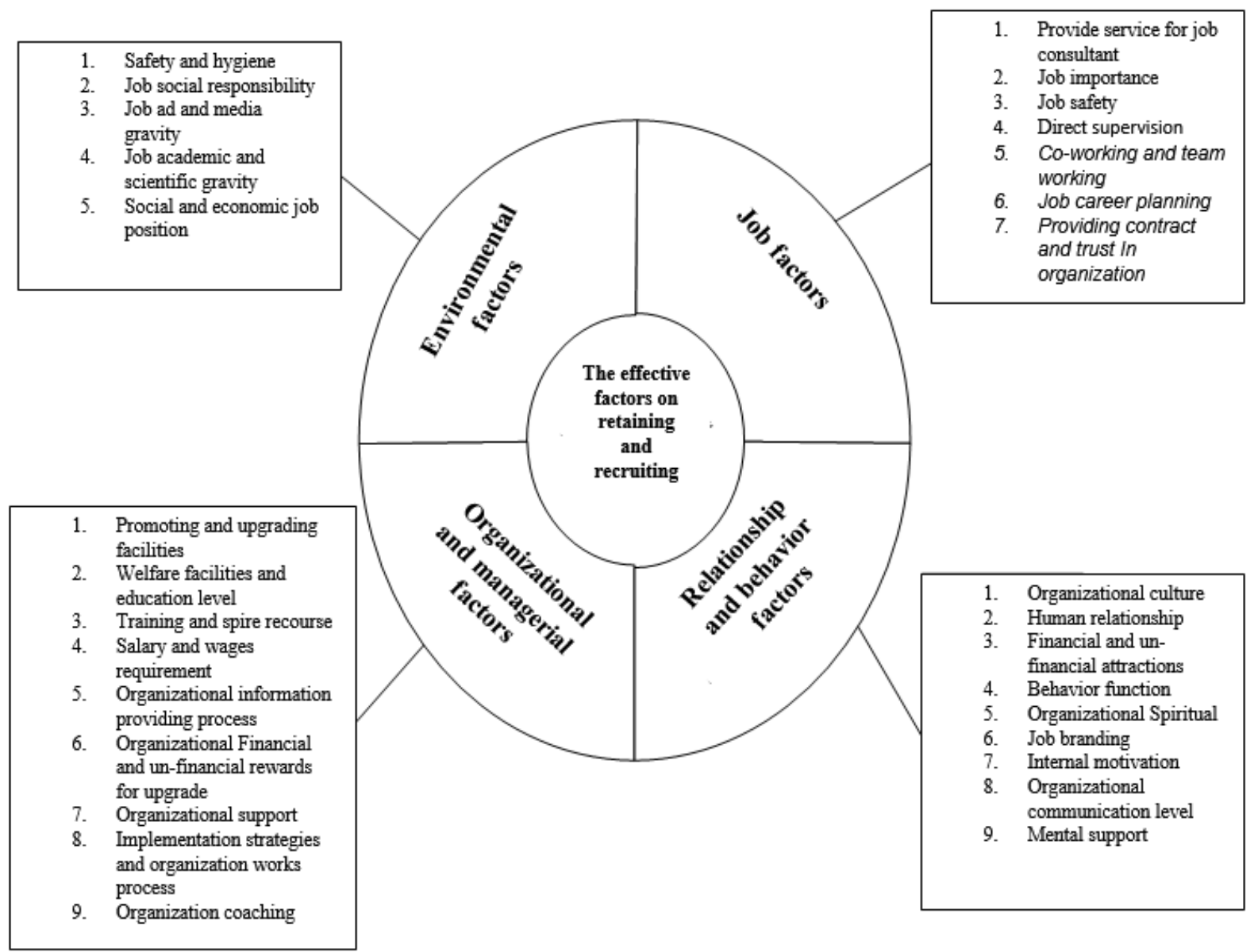

Fig. 1. Conceptual model

\section{Research hypothesis}

It is possible that there are the effective factors on recruiting and retaining professional physician in the management of social remedy security to organizational talent durability. 


\subsection{Research sub-hypotheses.}

1. Paying attention to the effective factors on recruiting and retaining professional physicians in the behavior and relationship factors dimension can provide organizational talent durability.

2. Paying attention to the effective factors on recruiting and retaining professional physicians in managerial and organizational factors dimension can provide organizational talent durability.

3. Paying attention to the effective factors on recruiting and retaining professional physicians in environmental factors dimension can provide organizational talent durability.

4. Paying attention to the effective factors on recruiting and retaining professional physicians in job factors dimension can provide organizational talent durability.

5. There is a significant difference between the effective factors on recruiting and retaining male and female professional physicians.

\section{Research methodology}

This research in terms of type is a qualitative research and in terms of aim is a practical research, on the other hand, because, in this study, we would examine the factors and sub-factors of recruiting and retaining, in terms of research mythology is a descriptive research that the suitable method for descriptive research is a survey method. The time domain: this research is sectional and the evidence and information and results of this study are examined in 1394. In this study, to collect the data and secondary data and registering organization's implied information and separating personal perceptions of reality and its analysis take place via direct observation the evidence, information in the database and the related literature through the study and taking notes and providing tables. As well as for gaining the others related information with the title through interviews with managers and staff experts will be examined in this area. Statistical society for this study is divided as follows:
The professional physician in the management of social security treatment in Tehran and its subordinate units in the provinces of Tehran that were been activated in 1394 that were about 1272. Due to Morgan table in the $95 \%$ confidence level, between 1272 peoples in the mentioned society, 259 people were selected as research sample and were defined the sample size. In this study, to test the hypothesis in inferential statistics and to count the level and comparing the samples from T-test and ratio (Binomial) and comparison of two community test and Mann-Whitney test to determinate about collecting data and from Friedman test to rank the variables of the sample group and testing the hypothesis was used.

\section{Findings}

6.1. Correlation test for variables. Question: is there a correlation relationship between the retaining and recruiting factors?

For examining the correlation between the research's variables, we can use many tests. If the variables weren't independent, they have the relationship together. In Ka-Square test correlation or lack of correlation are examined. But with the correlation coefficient shows exactly amount, direction and the type of relationship. With using the results of Spearman correlation coefficient test between research variables we can express the relationship between the model variables and examined the research hypothesis very exactly. Table 2 shows spearman correlation coefficient between the variables. Due to the collected results, there is only the correlation between the behavioral factors and managerial and organizational factors. As well as, there is the correlation between managerial and organizational factors and occupational factors and the other variables do not have any correlation between the variables in the areas of recruitment and retention and are independent of each other. This issue shows that the examination of depending variables is possible in retaining and recruiting factors.

Table 2. Correlation matrix of variables (Spearman coefficient)

\begin{tabular}{|c|c|c|c|c|c|c|c|c|}
\hline \multirow{2}{*}{ Variable name } & \multicolumn{2}{|c|}{ Behavioral and relational factors } & \multicolumn{2}{|c|}{$\begin{array}{l}\text { Managerial and organizational } \\
\text { factors }\end{array}$} & \multicolumn{2}{|c|}{ Environmental factors } & \multicolumn{2}{|c|}{ Job factors } \\
\hline & Correlation & Significance level & & & & & & \\
\hline $\begin{array}{l}\text { Behavioral and } \\
\text { relational factors }\end{array}$ & 1 & 5 & & & & & & \\
\hline $\begin{array}{l}\text { Managerial and } \\
\text { organizational } \\
\text { factors }\end{array}$ & $-0.053 * *$ & 0.211 & 1 & & & & & \\
\hline $\begin{array}{l}\text { Environmental } \\
\text { factors }\end{array}$ & $0.283 * *$ & 0 & $0.2338 * *$ & 0 & 1 & & & \\
\hline Job factors & $-0.256 * *$ & 0 & $-0.201 * *$ & 0.089 & 0.011 & 0.805 & 1 & \\
\hline
\end{tabular}

Note: Correlation is confirmed at the level of error of less than $0.01 * *$.

6.2. Binomial test, Friedman and Mann-Whitney for research questions. For testing difference hypothesis, when it would use from non-parametric tests, that our data are in assessing the nominal and ordinal level. These tests include tests that we are going to compare the observed distribution in a society with its theoretical distribution that its aim is comparing middle observed value in a society with its 
theoretical value. Due to the measurement scale is ordinal, data distribution is not normal, so it only selected accidental data, so it would use from binomial test. According to mentioned questions and hypothesis, it's time for examining and identifying the effects and non-effects one variables to a special event in the effective factors on retaining and recruiting area. By using the non-parametric method and binomial test (relative), the sub-factors that are effective toward retaining and recruiting professional physician in the management of social security in Tehran province and its subordinate units.

The most important sub-factors of behavioral and relational factors, managerial and organizational factors, environmental factors and occupational factors in the organization, in this case study, are defined by a special ratio in society as zero hypothesis. In Table 3 , the most important sub-factors with $p$ ratio that due to the determined hypothesis in $95 \%$ confidence level and in 5\% error level is defined are revealed. the ratio comparing is considered 0.6 because of the ratio and divided by three options (very poor, poor, average that all of them are a sign as not affecting on that variable) to 5 options that was calculated 0.6 and how much the ratio obtained would be higher than 0.6 , it has a lower effect on that the variables and vice versa. The binomial test (relative) for identifying the most important sub-factors of behavioral and relational factors from the perspective of physicians.

Question 1: Are behavioral and relational factors effective for recruiting and retaining professional physicians?

For identification the most important sub-factors of behavioral and relational factors from the perspective of physicians, due to above question, the acceptance period is assumed the 0.6 ratio and can be examined by non-parametric method.

Binomial test (relative). Table 3 in $95 \%$ confidence level and in $5 \%$ error level would specify the most important sub-factors. In order to accept and reject the zero hypothesis, it must specify the significance level if the result were in this domain and its significance level was over $5 \%$, it means that test and its variable are accepted, but, in other case, are not.

Table 3. The most important sub-components of behavioral and relational factors from the perspective of physicians

\begin{tabular}{|c|c|c|c|c|c|c|}
\hline Row & Main components & Sub-components & Test & Test ratio & Result & Significance level ( $p$-value) \\
\hline 1 & \multirow{8}{*}{$\begin{array}{l}\text { Behavioral and } \\
\text { relational factors }\end{array}$} & Financial incentives and non-financial of behavioral performance & Ratio & 0.6 & Accepted & 0.446 \\
\hline 2 & & Organizational Spirituality & Ratio & 0.6 & Accepted & 0.068 \\
\hline 3 & & Job brand & Ratio & 0.6 & Accepted & 0.445 \\
\hline 4 & & Internal motivation & Ratio & 0.6 & Accepted & 0.445 \\
\hline 5 & & Organizational communication levels & Ratio & 0.6 & Accepted & 0.449 \\
\hline 6 & & Mental support & Ratio & 0.6 & Accepted & 0.145 \\
\hline 7 & & Organizational culture & Ratio & 0.6 & Accepted & 0.325 \\
\hline 8 & & Human relationship & Ratio & 0.6 & Rejected & 0.023 \\
\hline
\end{tabular}

The results show that in the behavioral and relational factors dimension, financial incentives and nonfinancial of behavioral performance. Organizational spirituality, job branding, organizational communication level, organizational culture and mental support, all of those are the components of subfactors and are effective on retaining and recruiting professional physicians and, in the perspective of the professional physician, the factor of human relationship is not accepted.

Binomial test (relative) to identification of the most important sub-factors of organizational and managerial factors in the view of the professional physician.

Question 2: Do organizational and managerial factors are effective on retaining and requiring of the professional physicians? To identify the most and main important sub-factors of organizational and managerial factors in the view of the professional physicians due to above question, the assumption acceptance level is 0.6 and can be tested with use of none-parametric and the binomial test. Table 4 in $95 \%$ confidence level and in 5\% error level specify the main components. For the examination of acceptance and rejection of zero hypothesis, the significance level should be determined, so due to the findings and results if the results were in this domain and the significance level was over $5 \%$, it shows that the test and the mentioned variable is accepted and in another case is not.

Table 4. Main sub-components of Managerial and organizational factors from the perspective of physicians

\begin{tabular}{|c|l|l|c|c|c|c|}
\hline Row & Main components & \multicolumn{1}{|c|}{ Sub-components } & Test & Test ratio & Result & Significance level $(p$-value) \\
\hline 1 & \multirow{2}{*}{$\begin{array}{l}\text { Managerial and } \\
\text { organizational }\end{array}$} & The possibility for promotion and upgrading & Ratio & 0.6 & Accepted & 0.195 \\
\cline { 4 - 8 } & Educational level and welfare facilities & Ratio & 0.6 & Accepted & 0.315 \\
\cline { 3 - 8 } & & Training and individual promoting & Ratio & 0.6 & Accepted & 0.240 \\
\hline
\end{tabular}


Table 4 (cont.). Main sub-components of Managerial and organizational factors from the perspective of physicians

\begin{tabular}{|c|c|c|c|c|c|c|}
\hline Row & Main components & Sub-components & Test & Test ratio & Result & Significance level ( $p$-value) \\
\hline 5 & \multirow{6}{*}{$\begin{array}{l}\text { Managerial and } \\
\text { organizational } \\
\text { factors }\end{array}$} & Motivate wages and salary & Ratio & 0.6 & Accepted & 0.659 \\
\hline 6 & & Providing organizational information process & Ratio & 0.6 & Rejected & 0.004 \\
\hline 7 & & Organizational coaching & Ratio & 0.6 & Accepted & 0.050 \\
\hline 8 & & Administrative policies and procedures of the organization's work & Ratio & 0.6 & Rejected & 0.007 \\
\hline 9 & & Financial and none-financial rewards for organization upgrading & Ratio & 0.6 & Accepted & 0.845 \\
\hline 10 & & Organizational support & Ratio & 0.6 & Accepted & 0.225 \\
\hline
\end{tabular}

The results show that in environmental factors dimension, healthy and safety,social responsibility jobs, media attractions and advertising jobs, scientific attractions and academic jobs and the social status and economic jobs are components of sub-factors and are effective on retaining and recruiting professional physicians.

Binomial test (relative) to examinations the most important of job factors from the perspective of the professional physicians.

Question 3: Are job factors effective on retaining and recruiting professional physicians?

In order to examine the most important sub- components of job factors from the perspective of professional physicians according to the above question, the accepted domain is assumed 0.6 ratio and can be tested using the noneparametric method and binomial test (relative). Table 5 in 95\% confidence level and in 5\% error level can specify the most important subcomponents. In order to examine to the acceptance and rejection of zero hypothesis, the significance level should determine that if with the collected results were in this domain and its significance level was over $5 \%$, it shows that the test and the mentioned variable are accepted and in another case are not.

Table 5. The most important job of the sub-components ethics from the perspective of physicians

\begin{tabular}{|c|c|c|c|c|c|c|}
\hline Row & Main components & Sub-components & Test & Test ratio & Result & Significance level ( $p$-value) \\
\hline 1 & \multirow{7}{*}{ Job factors } & Providing job Consultation services & Ratio & 0.6 & Accepted & 0.128 \\
\hline 2 & & Job importance & Ratio & 0.6 & Accepted & 0.145 \\
\hline 3 & & Job safety & Ratio & 0.6 & Accepted & 0.075 \\
\hline 4 & & Direct supervision & Ratio & 0.6 & Accepted & 0.420 \\
\hline 5 & & colleagues and team working & Ratio & 0.6 & Accepted & 0.253 \\
\hline 6 & & Job career planning & Ratio & 0.6 & Rejected & 0.020 \\
\hline 7 & & Providing truth and contracting service in the organization & Ratio & 0.6 & Accepted & 0.175 \\
\hline
\end{tabular}

The results show that in job factors dimension, providing job consultation services, job importance, job safety, direct supervision colleagues and team working, job career planning, providing truth and contracting service in the organization, all of these are components of sub-factors and are effective on retaining and recruiting professional physicians. Friedman test determines the importance and ranking of each component and the sub-components of retaining and recruiting factors.
Question 4: what is the professional physician's opinion about the importance of each component and the sub-components retaining and recruiting factors.

To identifying the most important sub-components of retaining and recruiting factors due to above question by using Friedman test can be tested. Table 6 to 10 in 95 confidence level and in 5\% error level are ranking the most important sub-factors.

Table 6. Ranking sub-components of behavioral and relational factors from the perspective of physicians (Friedman test)

\begin{tabular}{|c|c|c|c|c|c|}
\hline Row & Main components & Sub-components & Test & Average ranking & Rank \\
\hline 1 & \multirow{8}{*}{ Behavioral and relational factors } & Intrinsic motivation & Friedman & 20.41 & 1 \\
\hline 2 & & Job branding & Friedman & 18.33 & 2 \\
\hline 3 & & Mental support & Friedman & 16.24 & 3 \\
\hline 4 & & Financial and nonfinancial incentives behavioral performance & Friedman & 15.32 & 4 \\
\hline 5 & & Organizational spirituality & Friedman & 15.31 & 5 \\
\hline 6 & & Organizational culture & Friedman & 14.98 & 6 \\
\hline 7 & & Organizational communication levels & Friedman & 11.94 & 7 \\
\hline 8 & & Human relationships & Friedman & 11.43 & 8 \\
\hline
\end{tabular}


Table 7. Ranking sub-components of managerial and organizational factors from the perspective of physicians (Friedman test)

\begin{tabular}{|c|c|c|c|c|c|}
\hline Row & Main components & Sub-components & Test & Average ranking & Rank \\
\hline 1 & \multirow{10}{*}{ Managerial and organizational factors } & Spire benefits and advantages & Friedman & 19.77 & 1 \\
\hline 2 & & attractive salary and wages & Friedman & 18.79 & 2 \\
\hline 3 & & Education level and welfare facilities & Friedman & 18.36 & 3 \\
\hline 4 & & The possibility of development and upgrading & Friedman & 16.18 & 4 \\
\hline 5 & & Organizational Financial and none-financial rewards for upgrading & Friedman & 15.97 & 5 \\
\hline 6 & & Training and individual promotion & Friedman & 15.88 & 6 \\
\hline 7 & & Organizational Coaching & Friedman & 15.38 & 7 \\
\hline 8 & & Organizational support & Friedman & 13.99 & 8 \\
\hline 9 & & Administrative policies and procedures of the organization's work & Friedman & 13.82 & 9 \\
\hline 10 & & Organizational information providing process & Friedman & 13.02 & 10 \\
\hline
\end{tabular}

Table 8. Ranking sub-components of environmental factors from the perspective of physicians (Friedman test)

\begin{tabular}{|c|c|c|c|c|c|}
\hline Row & Main components & Sub-components & Test & Average ranking & Rank \\
\hline 1 & \multirow{5}{*}{ Environmental factors } & Healthy and safety & Friedman & 19.33 & 1 \\
\hline 2 & & Social and economic status of Jobs & Friedman & 18.37 & 2 \\
\hline 3 & & Job Social Responsibility & Friedman & 17.94 & 3 \\
\hline 4 & & Academic and scientific jobs attractions & Friedman & 17.65 & 4 \\
\hline 5 & & Media and advertising jobs attractions & Friedman & 17.39 & 5 \\
\hline
\end{tabular}

Table 9. Ranking the sub-components of occupational factors from the perspective of physicians

(Friedman test)

\begin{tabular}{|c|c|c|c|c|c|}
\hline Row & Main components & Sub-components & Test & Average ranking & Rank \\
\hline 1 & \multirow{7}{*}{ Job factors } & Job safety & Friedman & 19.69 & 1 \\
\hline 2 & & Job career planning & Friedman & 19.42 & 2 \\
\hline 3 & & Job importance & Friedman & 18.9 & 3 \\
\hline 4 & & Direct supervision & Friedman & 18.4 & 4 \\
\hline 5 & & Colleagues and team working & Friedman & 17.96 & 5 \\
\hline 6 & & Providing job consultation services & Friedman & 17.85 & 6 \\
\hline 7 & & Providing truth and contracting service in the organization & Friedman & 17.19 & 7 \\
\hline
\end{tabular}

Table 10. Ranking the main component of retaining and recruiting factors from the perspective of physicians (Friedman test)

\begin{tabular}{|c|l|l|c|c|}
\hline Row & \multicolumn{1}{|c|}{ Main components } & \multicolumn{1}{|c|}{ Test } & Average ranking & Rank \\
\hline 1 & Managerial and organizational factors & Friedman & 3.09 & 1 \\
\hline 2 & Behavioral and relational factors & Friedman & 2.53 & 2 \\
\hline 3 & Job factors & Friedman & 2.37 & 3 \\
\hline 4 & Environmental factors & Friedman & 2.01 & 4 \\
\hline
\end{tabular}

\section{Conclusion}

In the similar researches (Rahmanpour, 1379) and (Zare, 1384) and (Ghazizadeh, 1387), etc., by using the interview and questionnaire tools, the retaining and recruiting factors in the realm of schools, universities, institutes and scientific research and organizations focused on education, government agencies and industrial companies were examined that the results show these factors effect on person performance directly and as well as job and managerial factors play an important role to determining the retaining and recruiting factors in the organization. That without an integrated system that provides the person, organization and society needs from different aspects like economic, political, doctrinal, will not continue its life. In general, we can express that human capital is an important and vital resource for the organizational life in the future. Overall, we can claim that considering the retaining and recruiting factors causes to enhancing business process efficiency, organizational and individual development, organizational growth and existence the main factors are a guarantee increase effectiveness and it seems that this topic is required to more working and efforts. An additional of concerns about lacking the ethic privacy in media cause that many activities are going to face with many challenges and getting effects from them. As well as organizational factors and organizational structures, 
organizational culture, education and information system, all of those are more effective on the organization growth and the managers by having professional ethics and values and beliefs would reach to this belief that intellectual growth and their job are required to having suitable talent.

\section{References}

1. Ghazizadeh, Mustafa, Amani, Jamshid, Khosrow Karimi, Hossein. (2013). Factors affecting organizational sustainability manpower, Bimonthly Scientific Journal of Shahed University, 29, p. 1387.

2. Kaplly, Peter. (2008). Market-oriented approach to retain talent. Luqman Rahmanpour Vnahyd Amrollahi [Translator], Journal Tact, (107), p. 44.

3. Zare, Mohsen. (2004). Relationship between organizational culture and the retention of skilled staff view the teaching hospitals affiliated to Hamadan University of Medical Sciences and Health Services, Scientific Journal of Hamadan University of Medical Sciences and Health Services.

4. Robbins, P. Stephen. (2003). Principles of Organizational Behavior. USA: Strayer University.

5. Zare, M., Maher, A., Vatankhah, S. [Barrasye ertebate farhange sazmani ba hefz va negahdashte nirooye ensanye motokhases az didgahe karkonane bimarestanhaye omoomye amoozeshye tabeaeye daneshghe oloom pezeshki va khadamate behdashti darmanye Hamedan-1384]. [Dissertation]. Iran University of Medical Sciences, Tehran; 2005.

6. Bhatnagar, J. (2007). Talent management strategy of employee engagement in Indian ITES employees: key to retention, Employee Relation, 29 (6), pp. 640-663.

7. Guthridge, M., Komm, A.B. \& Lawson, E. (2006). The people problem in talent management, The McKinsey Quarterly, 2, pp. 6-12.

8. Hartley, D. (2004). Tools for Talent, Training and Development, 58 (4), pp. 20-23.

9. Sandler, S. (2003). The changing face of talent management, HR Focus, 80 (5), pp. 1-4.

10. Tulgan, B. (1996). Managing generation X. Oxford: Capstone.

11. Michaels, E., Handfield, J. (2001). The war for Talent. New York: Mckinsey. 